Original Article

\title{
Motor cortex somatotopic presentation after restriction of neck movement in rats
}

\author{
Yoshinito Sekiguchi RPT, MS ${ }^{1)^{*}}$, Ken Muramatsu RPT, PhD ${ }^{2)}$, Toru Tamaki RPT, PhD ${ }^{1)}$, \\ Masako IKutomo RPT, PhD ${ }^{3)}$, KazUo Kurosawa RPT, $\mathrm{PhD}^{4)}$ \\ 1) Department of Physical Therapy, Health Science University: 7187 Kodachi, Fujikawaguchiko-machi, \\ Yamanashi 401-0380, Japan \\ 2) Department of Physical Therapy, Kyorin University, Japan \\ 3) Department of Physical Therapy, University of Tokyo Health Sciences, Japan \\ 4) Department of Physical Therapy, International University of Health and Welfare, Japan
}

\begin{abstract}
Purpose] In this study, we aimed to investigate the effects of neck movement restriction on somatotopic mapping of the motor cortex. We restricted cervical extension for two weeks and investigated the effects on motor cortex somatic representation in rats. [Subjects and Methods] We placed six Wistar rats into each of three groups: (i) the experimental group, in which cervical extension was restricted; (ii) the sham group, in which cervical movement was not restricted, but a splint was placed in the shoulder girdle; and (iii) the control group. After cervical immobilization for two weeks, we evaluated the motor cortex somatic representation using intra-cortical micro-stimulation. [Results] In the experimental group, the areas of the cervical and vibrissal domains of the motor cortex decreased by approximately $50 \%$, and the forelimb domain showed slight reduction. In addition, a trunk domain formed at the locus of the vibrissal area. There were no differences between the sham and control groups. [Conclusion] Restriction of cervical extension for two weeks resulted in changes in motor cortex somatic representation. Reversible changes occurred in cortical areas that controlled the neck and parts of the body involved in cervical movement.

Key words: Motor cortex, Representation, Neck restriction
\end{abstract}

(This article was submitted May 7, 2019, and was accepted Jul. 4, 2019)

\section{INTRODUCTION}

The neck has many functions, including supporting the head, maintenance of balance, and controlling movements that aid in directing eyesight. Therefore, neck injuries can have effects on movements of the whole body, as represented by the involvement of the neck in controlling balance ${ }^{1-3)}$. As such, the neck is one of the most important joints with regards to investigating therapeutic strategies by physiotherapists. However, research on functional abnormalities of the neck has only been carried out from a biomechanical perspective and there has been no previous research relating to the effects of neck injury on the central nervous system ${ }^{4,5)}$. In particular, it is known that, as the origin of the corticospinal tract, the motor cortex not only controls voluntary movement, but also has high neuroplasticity, enabling rapid reorganization after injury. The motor cortex is thought to undergo changes after neck injuries, but the nature of these changes is completely unknown ${ }^{6,7}$.

In the present study, the necks of rats were immobilized for 2 weeks and the effects on motor cortex somatic representation were investigated.

*Corresponding author. Yoshihito Sekiguchi (E-mail: y-sekiguchi@kenkoudai.ac.jp)

(C2019 The Society of Physical Therapy Science. Published by IPEC Inc.

(c) (1) $\odot$ This is an open-access article distributed under the terms of the Creative Commons Attribution Non-Commercial No DerivacC. ${ }_{\mathrm{BY}}$ NG ND tives (by-nc-nd) License. (CC-BY-NC-ND 4.0: https://creativecommons.org/licenses/by-nc-nd/4.0/) 


\section{SUBJECTS AND METHODS}

The study was carried out with 13-week-old male Wistar rats with weights ranging from 294 to $322 \mathrm{~g}$. There were 6 rats allocated to each of the experimental, sham, and control groups. In the experimental group, the shoulder girdles were immobilized using orthopedic casts, such that only cervical extension was restricted (Fig. 1A). In the sham group, splints were fixed to the shoulder girdles, but cervical movement was not restricted (Fig. 1B). In the control group, no splints were applied (Fig. 1C).

After 2 weeks, mapping of the motor cortex of rats in each group was carried out by intra-cortical micro-stimulation using a previously established method ${ }^{8,9}$. First, anesthesia was maintained using a combination of $70 \mathrm{mg} / \mathrm{kg}$ ketamine hydrochloride and $5 \mathrm{mg} / \mathrm{kg}$ xylazine, administered intraperitoneally. If necessary, an additional $20 \mathrm{mg} / \mathrm{kg} \mathrm{ketamine} \mathrm{and} 0.02 \mathrm{mg} /$ $\mathrm{kg}$ acepromazine was administered intraperitoneally. Next, the neck of each rat was immobilized using a fixation device and body temperature was maintained at $37^{\circ} \mathrm{C}$. After making an incision through the scalp, the right part of the skull was removed, exposing the right sensory-motor cortex. Then, $40-\mathrm{k} \Omega$ tungsten microelectrodes (Unique Medical, Tokyo, Japan) were inserted at $500-\mu \mathrm{m}$ intervals, extending from the cerebral surface to a depth of $1,800 \mu \mathrm{m}$, which corresponds to layers IV-V of the cortex. Stimulation was delivered for $30 \mathrm{~ms}$ with a square wave at a frequency of $333 \mathrm{~Hz}$ and a duration of $300 \mu \mathrm{s}$ using an SEN-7130 stimulator (Nihon Kohden, Tokyo, Japan) and an SS-04 J isolator (Nihon Khoden). The electric current was then gradually increased until bodily movement could be identified. The minimum current strength at which movement of a body part was induced was recorded as the threshold value. No bodily movement was observed with currents up to 50 $\mu \mathrm{A}$. As such, $0-50 \mu \mathrm{A}$ was defined as the no-response range. Mapping was carried out in 56 loci on the right side of the bregma. The responsive region had an area of $0.25 \mathrm{~mm}^{2}$ and the distribution of cortical domains for different parts of the body and the areas of each were obtained.

This study was approved by Health Science University's Experimental Animal Committee (approval no.17-002).

Data are presented as mean \pm standard deviation. The values in each group were compared by one-way analysis of variance and multiple comparisons were carried out by the Bonferroni method for the test of the lower position.

\section{RESULTS}

Within several hours after fitting the splints, rats in the experimental and sham groups had acclimatized to attachment of the foreign item and were calm and quiet in their cages. The rats in the experimental group initially compensated for the restricted cervical extension by either rotating the neck or extending the trunk, but by 1 or 2 days after attachment of the splint, all rats compensated for the restriction by extending the trunk. No changes in food or water intake were found during the immobilization period and no differences in body weight were observed after 2 weeks (Table 1).

Major changes were found in the somatotopy of the motor cortex after cervical immobilization. In the experimental group, the areas $\left(\mathrm{mm}^{2}\right)$ of the cervical and vibrissal domains of the motor cortex decreased by approximately $50 \%$ (Table 1, Fig. 2; $\mathrm{p}<0.001$ ) compared to the control and sham groups, and the forelimb domain showed a slight loss of area (Table 1, Fig. 2; $\mathrm{p}<0.05$ ) compared to the control group. In addition, a trunk domain that was not present in the other two groups had formed on the medial side of the motor cortex in experimental group rats (Fig. 2C). Furthermore, the changes were not only in area, as the forelimb and trunk domains encroached upon and replaced the cervical and vibrissal domains in the experimental
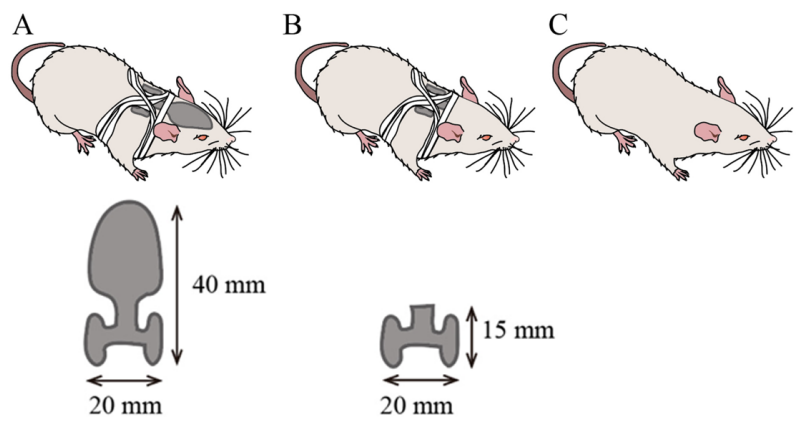

Fig. 1. Cervical immobilization using a splint.

A: Experimental group: A splint approximately $40 \mathrm{~mm}$ long extending from an $\mathrm{H}$-shaped splint with a width of $20 \mathrm{~mm}$ was immobilized with orthopedic plaster, to prevent cervical extension.

B: Sham group: Only the H-shaped splint was immobilized in the area surrounding the shoulder girdle. Cervical movement was not restricted.

C: Control group: Rats were not fitted with a splint. 
Table 1. Mean body weights, motor cortex areas, and threshold values in the control, sham and experimental groups

\begin{tabular}{|c|c|c|c|}
\hline & Control $(\mathrm{n}=6)$ & Sham $(n=6)$ & Experimental $(n=6)$ \\
\hline \multicolumn{4}{|l|}{ Body weight (g) } \\
\hline 13-weeks-old (pre-restriction) & $308.5 \pm 9.1$ & $306.8 \pm 13.2$ & $307.1 \pm 10.9$ \\
\hline 15-weeks-old (post-restriction) & $319.1 \pm 9.1$ & $313.8 \pm 9.1$ & $310.6 \pm 6.7$ \\
\hline \multicolumn{4}{|l|}{ Neck domain } \\
\hline Area $\left(\mathrm{mm}^{2}\right)$ & $1.3 \pm 0.2$ & $1.1 \pm 0.3$ & $0.5 \pm 0.1^{* * *+\dagger \dagger}$ \\
\hline Threshold $(\mu \mathrm{A})$ & $20.4 \pm 4.9$ & $21.7 \pm 5.0$ & $20.6 \pm 5.6$ \\
\hline \multicolumn{4}{|l|}{ Forelimb domain } \\
\hline Area $\left(\mathrm{mm}^{2}\right)$ & $4.5 \pm 0.3$ & $4.1 \pm 0.3$ & $3.9 \pm 0.5^{*}$ \\
\hline Threshold $(\mu \mathrm{A})$ & $22.5 \pm 2.6$ & $21.3 \pm 3.1$ & $22.7 \pm 5.0$ \\
\hline \multicolumn{4}{|l|}{ Vibrissal domain } \\
\hline Area $\left(\mathrm{mm}^{2}\right)$ & $3.3 \pm 0.3$ & $3.2 \pm 0.3$ & $0.9 \pm 0.5^{* * *+\dagger \dagger}$ \\
\hline Threshold $(\mu \mathrm{A})$ & $22.1 \pm 3.5$ & $22.3 \pm 5.0$ & $23.2 \pm 7.3$ \\
\hline \multicolumn{4}{|l|}{ Trunk domain } \\
\hline Area $\left(\mathrm{mm}^{2}\right)$ & 0 & 0 & $0.3 \pm 0.2^{* * \dagger \dagger}$ \\
\hline Threshold $(\mu \mathrm{A})$ & - & - & $43.9 \pm 3.9$ \\
\hline \multicolumn{4}{|l|}{ Jaw domain } \\
\hline Area $\left(\mathrm{mm}^{2}\right)$ & $0.8 \pm 0.3$ & $0.8 \pm 0.3$ & $1.0 \pm 0.7$ \\
\hline Threshold $(\mu \mathrm{A})$ & $24.1 \pm 9.8$ & $25.9 \pm 4.6$ & $23.5 \pm 6.2$ \\
\hline
\end{tabular}

group. In these domains, when stimulation was applied above the threshold values (higher than $50 \mu \mathrm{A}$ ), the movement essential to the original domain was observed, whereas when the stimulation strength was reduced below this threshold only movements associated with the new domain occurred. For example; when the medial side of the motor cortex was stimulated with a current higher than the threshold value within certain domains, movement occurred in the vibrissae and trunk, whereas when the current strength was reduced below the threshold, only trunk movement occurred. In contrast, no changes were found in the area of the jaw domain or in the threshold values for any domains (Table 1).

\section{DISCUSSION}

This study showed that restricting cervical extension in rats resulted in a marked decrease in the areas of the cervical and vibrissal domains of the motor cortex and slight decrease in the area of the forelimb domain. In addition, rats with an immobilized neck exhibited a new trunk domain that formed rostral to the bregma, whereas the trunk domain is distributed entirely to the caudal side of the bregma in normal rats9). Taking into consideration our observation that changes in motor cortex somatotopy in the experimental group were different from changes in motor cortex somatotopy that have been shown to be dependent on depth of anesthesia ${ }^{10)}$, and that no similar phenomenon was found in the motor cortex in the sham group, it is reasonable to conclude that the changes in motor cortex somatic representation observed in this study were due to restriction of cervical extension. It is also possible that these motor area size alterations resulted from reduced motor activity or anorexia caused by stress of restriction rather than direct restriction. However, this is unlikely because there is no significant difference of body weight gain among the 3 groups after 4 weeks in the type 1 diabetic model. This model showed severe reduced motor activity, but did not show alteration of the cervical, forelimb, or vibrissal motor area ${ }^{8}$. Previous studies have shown that motor cortex somatic representation changes in an activity dependent manner ${ }^{7,11)}$. Therefore we concluded that it was cervical movement restriction and compensatory trunk movement that resulted in reduction and expansion of the domains responsible for cervical and trunk movement, respectively. In addition, it is possible that reduction of the vibrissal domain was due to decreased exploratory behavior using the vibrissae and that this functional restriction caused by the neck being immobilization was compensated for by forelimb movement, resulting in increased forelimb activity, and thus encroachment on the vibrissal domain by the forelimb domain. However, we did not measure the level of movement in this study, so this thought cannot be clarified.

As explained above, the mechanisms mediating changes in the motor cortex after cervical immobilization are unknown, but our finding that cervical immobilization for as short as 2 weeks changed somatic representation in the motor cortex supports the clinical observation that cervical dysfunction effects the entire body ${ }^{1-3)}$. In addition, there have been reports of changes in motor cortex somatic representation as soon as 1 hour after peripheral nerve transection. Therefore, it is possible that the changes in motor cortex somatic representation that we observed could have occurred much earlier than 2 weeks ${ }^{12}$. 

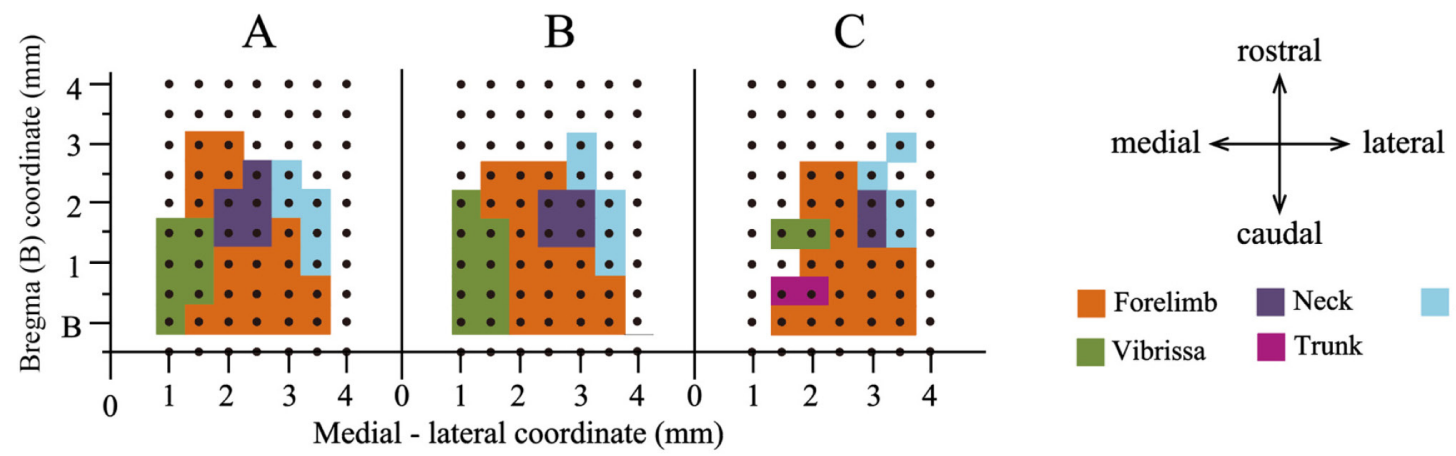

$\mathrm{D}$
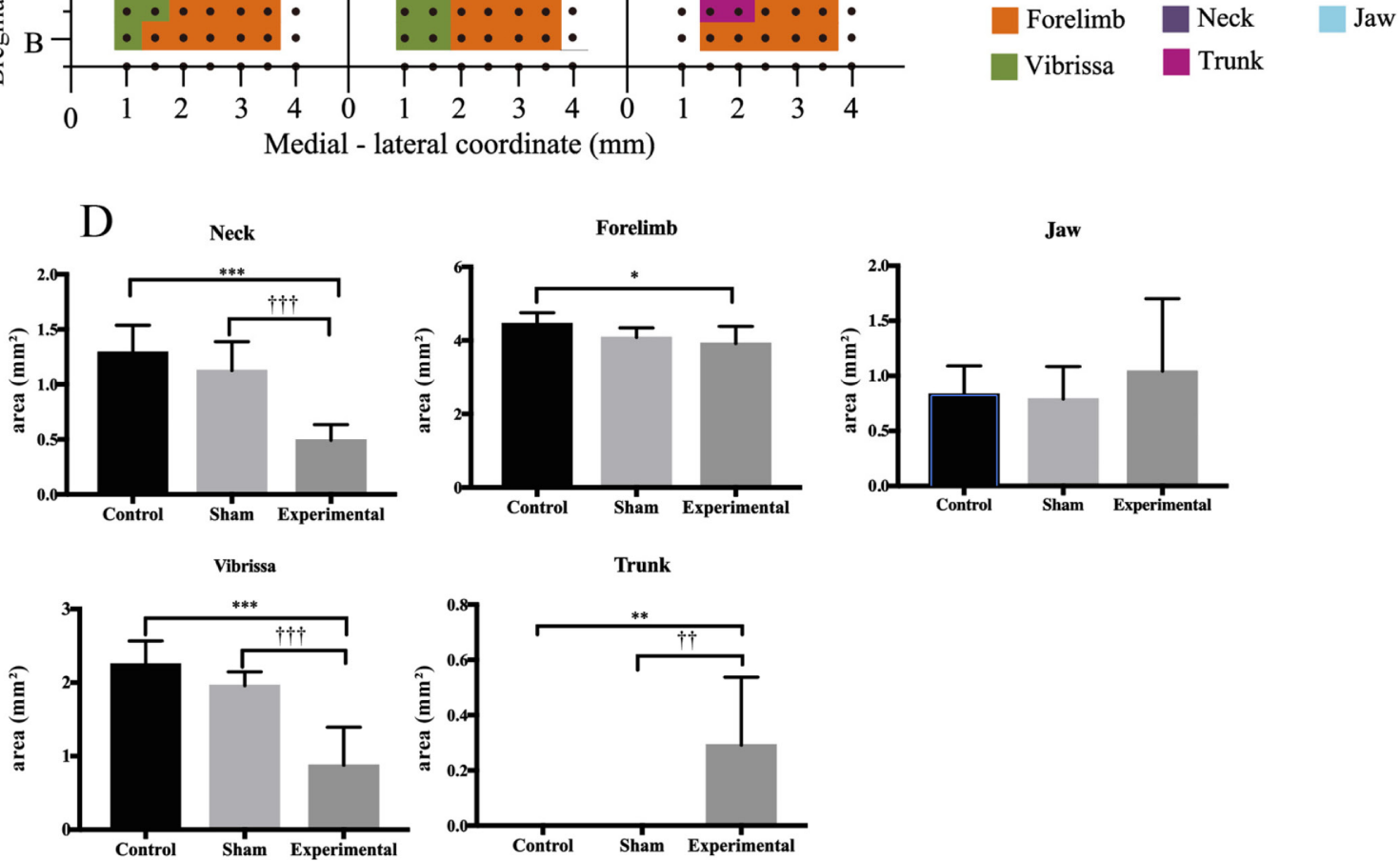

Fig. 2. Comparison of typical motor cortex somatic representation and domain areas.

A. Representative example of a coordinate map of the motor cortex showing body domain locations in a control rat.

B. Representative example of a coordinate map of the motor cortex showing body domain locations in a sham rat.

C. Representative example of a coordinate map of the motor cortex showing body domain locations in an experimental rat.

D. Comparisons of domain areas (in $\mathrm{mm}^{2}$ ) in the motor cortex across groups. No significant differences were found in any domain areas between the control and sham groups. The experimental group rats showed significant decreases in the areas of the cervical and vibrissal domains of the motor cortex, compared to control and sham rats, as well as a decrease in forelimb domain area compared to control rats. The regions in which area was decreased in the experiment rats were occupied by the forelimb domain and a newly formed trunk domain. ${ }^{*} \mathrm{p}<0.05$ (vs. control), ${ }^{* *} \mathrm{p}<0.01$ (vs. control), ${ }^{* * *} \mathrm{p}<0.001$ (vs. control), ${ }^{\dagger \dagger} \mathrm{p}<0.01$ (vs. sham), ${ }^{\dagger \dagger} \mathrm{p}<0.001$ (vs. sham).

This is the first study to clearly correlate changes in the nervous system with changes in whole body movement after cervical immobilization. The changes in motor cortex somatic representation found offer the potential for new interpretations on the pathology of patients with cervical motor disorders with regards to contributions of the motor cortex. It is hoped that progress on quantitative analysis of changes in movement after cervical immobilization and the effects of these changes on motor cortex somatic representation will be made in the future, and that the relationships with clinical symptoms will be more thoroughly investigated.

\section{Funding and Conflict of interest}

The authors have no conflicts of interest to declare.

\section{REFERENCES}

1) Treleaven J: Sensorimotor disturbances in neck disorders affecting postural stability, head and eye movement control. Man Ther, 2008, 13: 2-11. [Medline] [CrossRef]

2) Cheng $\mathrm{CH}$, Chien A, Hsu WL, et al.: Changes of postural control and muscle activation pattern in response to external perturbations after neck flexor fatigue in young subjects with and without chronic neck pain. Gait Posture, 2015, 41: 801-807. [Medline] [CrossRef] 
3) Treleaven J, Takasaki H, Grip H: Altered trunk head co-ordination in those with persistent neck pain. Musculoskelet Sci Pract, 2019, 39: 45-50. [Medline] [CrossRef]

4) Bogduk N, Yoganandan N: Biomechanics of the cervical spine Part 3: minor injuries. Clin Biomech (Bristol, Avon), 2001, 16: 267-275. [Medline] [CrossRef]

5) Cusick JF, Yoganandan N: Biomechanics of the cervical spine 4: major injuries. Clin Biomech (Bristol, Avon), 2002, 17: 1-20. [Medline] [CrossRef]

6) Shinoda Y, Sugiuchi Y, Izawa Y, et al.: Long descending motor tract axons and their control of neck and axial muscles. Prog Brain Res, 2006, 151: 527-563. [Medline] [CrossRef]

7) Nudo RJ, Plautz EJ, Frost SB: Role of adaptive plasticity in recovery of function after damage to motor cortex. Muscle Nerve, 2001, 24: 1000-1019. [Medline] [CrossRef]

8) Muramatsu K, Ikutomo M, Tamaki T, et al.: Effect of streptozotocin-induced diabetes on motor representations in the motor cortex and corticospinal tract in rats. Brain Res, 2018, 1680: 115-126. [Medline] [CrossRef]

9) Sekiguchi Y, Muramatsu K, Tamaki T, et al.: Neck and trunk representations in the primary motor cortex in rats. J Phys Ther Sci, 2019, 31: 608-611.

10) Tandon S, Kambi N, Jain N: Overlapping representations of the neck and whiskers in the rat motor cortex revealed by mapping at different anaesthetic depths. Eur J Neurosci, 2008, 27: 228-237. [Medline] [CrossRef]

11) Ganguly K, Poo MM: Activity-dependent neural plasticity from bench to bedside. Neuron, 2013, 80: 729-741. [Medline] [CrossRef]

12) Sanes JN, Suner S, Lando JF, et al.: Rapid reorganization of adult rat motor cortex somatic representation patterns after motor nerve injury. Proc Natl Acad Sci USA, 1988, 85: 2003-2007. [Medline] [CrossRef] 